\title{
Systemic Population and Family Education for National Security and Development
}

\author{
Auta, Filibus Jamaka \\ Department of Curriculum and Instructional Technology, \\ Federal College of Education(Technical), Gombe
}

Gombe State, Nigeria

\section{Doi:10.5901/jesr.2013.v3n5p135}

\begin{abstract}
Man's inclination to associate with others for the sheer pleasure of human interaction without thought of practical aims or other purposes remains natural. These increasingly task group socialization and expressions of family relativity. Evident are the developmental change, that occur within the family and population phenomenon. Family and population partisanship and roles have brought in primary, secondary and constitutional social groups. These have gradual culmination to group and individual roles. However, we realize that growth and development of individuals and group involvement and quality of life is embedded with conceptual difficulties of in-balance that affect peace, security partly from mindsets, national interests and aspirations, or unrests and insecurity through failures, wrong apprehension. Educational platforms are structures for elite society. Environmental enlightenment has options geared towards stabilizing institutional framework for security and critical development as enshrined in national interests and aspiration. This paper however, examines the roles of population and family social groups, their education and implication, and mindset that could ameliorate security problems, for enhance development.
\end{abstract}

Keywords: socio- constitutional family, unrests, security, stability, development, aspiration, interests

\section{Introduction}

It is no doubt that the present state of the family is under pressure of modernization and economic hardship as a result has lost control social mechanism, solidarity, cohesion and social security that was endowed. Family roles as a basic unit of economic activities for member and entire population has derailed. Recently, it is increasingly disrupted by social forces of migration, urbanization, modernization, that has over stressed the family than it can cope with. Could it be that our educational system are not working. The educational is facing general indictment. It has been over saddened with criticism. That the educational policy has produced young men and women without identifiable skills or specific profession. This in addition has exacerbated the general unemployment problems. The question that lingers among educationalists as a recurring decimal is, what is the relevance of our educational system to aspirations and the problems of individuals and society. The logical consequence of our failed system of education is the creation of a situation of unemployable educated Nigerians who sooner or later constitute natural hazards and crime prone citizens. Unless something drastic is done, institutions could become breeding grounds for future criminal elements, an issue of grave consequences to our national survival.

It is not out of place to say that Nigeria is endowed with human and natural resource to make it a wealthy nation. It entails that it is the people that can make the nation great by way in which they conduct their private and public affairs. They have to adhere to accepted practices and norms, national interest and aspiration. They need to develop towards economic social, political 
institutional stability. One way to achieve this is strict adherence to accepted norms, national interests and aspiration. To develop critical areas towards economic, social, political, institutional stability. There is the need for developmental mindsets to drive the economy forward. Presently, Nigeria is yet to answer the glorious name as a producer nation, as it still import food, a host of other materials. There is high level of unemployment, retrenchment, across the country. These are ready platform for fathering social disasters, as robbery, kidnap, assassinations, hatred and civil disobedience mostly in urban centers. How can the population be nurtured to ensure and guarantee national security is the issue. Modern development of the entire world is a fit that a society is kept constantly aware of what is happening every where. The dimension and perspectives of family and population activities are continually altered. The way in which we live is being modified at all times, as access to information, education life style have increased. Radio, television, satellite education are always around to prompt neighbor to neighbor Influence and access. Family, population and society, the community association think about nearly every issue, be it political, religion, government, culture, is almost exclusively influenced on daily base. The mindset has been altered. The transformation, development chain is an issue. Change and quality of living have become phenomenal issue, capable of being prone to security challenges. The population, individuals, the family increasingly call for freedom, protection, and Security, the elite society that we eventually found ourselves in present dispensation can no longer guard against espionage, sabotage, crimes, attacks and other forms of insecurity.

The causes of these crimes have been identified in contemporary literature of disciplines such as anthropology, psychiatry, social psychology, sociology and even history. Such literature rightly unveiled the process which individuals become criminals and theories of crimes, the relationship of crime rate to variations in culture and social organization as exhibited by the family and population. As crimes, different mindsets reflect the attributes of the people, the quality of life of family, population are determined by their capacity to commit crime. Psychologists believed that heredity and environment is the interaction of individual and society. The totality of human nature and experience encompasses elemental origin of crime.

\section{Meaning and Concept Analysis}

The word "Family" refers to a group of two or more people who are closely related by biological, sexual, adoptive or strong psychological or emotional bond, who regularly share resources and interact with one another, in an atmosphere of affection acceptance, intimacy, support and trust. They share common interests and aspiration. This is the position of Edna (2010). Marj (2006) postulates that looking at the family in its minimal form and widest sense as a basic kinship with all relatives living together is recognized as a social unit including adopted persons. Each has a role. To be concise, the core family is union of blood and tries of marriage. The bond in this case is that of husband and wife relationship well as a primary emphasis and centrality of blood relationship. The family behavior is based on mutual affection and consensus of its members. This to be properly nurtured towards accepted norms, to advert gradual inclination to insecurity and unrest by extension.

On the contrary, population is regarded as the total human inhabitants of specified area, such as city, country or continent presented at a given time. The Encyclopedia Britannica (2010) states that, the number given by statistical data of people living in an area, city, country subject to emigration and immigration influence and analysis is seen as population. The layman says population is all the people residing within a delimited geographic area, for example within a nation, a geographic region, a sate, a metropolitan area in a city. The residents are in a social structures organization within the population, if not well managed can generated complicity of insecurity and unrests.

The population and family relatively concept has numerous segment of social group formations based on common interests and occupational characteristics regarded as social group 
of constitutional family. From a consensus of primary family, secondary family in population theory, social group relativity concept can fit in other kinds of relationship in group organization, structure and skills, perception, abilities, attitudes and knowledge based development of individuals are achieved through formal and informal facilitating structure of education in population organization. Security is complimentary to population development.

The lack of security could base multiplicity of unrests. In general terms security, as applied to population mobility could be see as any means of device employed to guarantee emotional freedom, assurances, confirmation against loss, attack or harm, safely, other measures of security are of perceptions, safeguards etc. if there are not properly put in place could based unrests and insecurity. The Encyclopedia Britannica (2010) looks at security as any of the variety of means or devices designed against a range of hazards, including crime, fire, accidents, espionage, sabotage subversion and attack. The control of these for the security of the family, the population remains crucial to individual, national development and for control of unrests. The layman sees security as a state of being secure, freedom from danger, freedom from fear, protection, measures taken to guard against espionage or sabotage, crime, attack or escape. Therefore national security is assume to mean a state of a nation being secured.

\section{The Family Composition by Extension}

The core properties of life are growth change, reproduction, active resistance to external perturbation and capacity for transformation regarded as evolution. The associated science concept made efforts to circumvent a single definition of "life" has been worrisome. However, it is acknowledge that all living organisms have only one object, that of preserving constant conditions of "life". These conditions include:- Unity, evolution, diversity, continuity, behaviour and relationships. These factors are replicated in primary families of blood relationships and ties of marriage and Secondary family of social groups in population groups namely :-(1) The core family (2) Sub-families (3) Family of a lineage of people in succession (4) Family of offspring's or branches of an original (5) Family of people with something in common-origin, characteristics and occupation (6) Family of people living together harmoniously. It would be seen that group mentioned above in items five and six are capable of breaking into large formations from population perspectives which could agreeably identified recognized by the binding force of the commonality, law, constitution etc. socio- constitutional groups and family. These include :-

a. Economic interests groups and family like cooperative societies, chambers of commers, market places, trade fairs etc .

b. Political interests groups and family for example village, clan, town unions political parties, ethnic unions, alumni association etc .

c. Voluntary organization and family for example Rotary club, peoples club of Nigeria, Lions club, Lioness inner wheel, Zonta international, etc.

d. Educational family, groups of institutions for example school, colleges, universities, museums, libraries, cultural centers, art galleries, television viewing centers, etc.

e. Social clubs and constitutional relativity for example drinking clubs, fan cub, television viewers association, peoples club of Nigeria, Island club, and some of the voluntary organizations, etc.

f. Spiritual groups and family like religious groups, churches, mosques, temple, lodges, Idiong society, Ogboni, owegbe cult, witchcraft societies, shrines, pilgrimages, etc.

g. Social class group and family, like men only club, women only clubs, age grade, occupational or professional groups, (Nigerian union of teachers),NUT, Nigerian army officers wives association, women in Nigeria, women in politics, etc .

h. Recreational clubs and family such as sports, festivals, stadia, supporters club of Nigeria, Television viewers association, etc . 
i. Cultural groups and family for example masquerades groups, choral groups, Ekpo society, Oro, Akwaesop/maisong Ibibio, marriage ceremonies, cultural festivals, traveling theatres, and so on. These are classified social economic political educational and institutional families. Members in context experience giving,

Receiving, agreeing, disagreeing, pleasing, being pleased, one on one expressions Neighbour to neighbour influence and groups exploits, for the good of general society.

\section{Population and Family Education}

Contribution, roles of population, groups and individuals in areas such as contribution of education has raised the society to elite standards. People as purveyors of cultural reproductions etc, is a development which stem from educational orientation of environmental education which encompasses distance education, online course, home-schooling, centralized instruction distance learning, virtual learning, open learning in countries of Europe, Asia and the Americas.

Education within a family or a population is responsible for the behaviour expected of an Individual who suddenly occupies a given social position or status. His actions and qualities presents place him as an individual capable of dealing with situations and playing the roles of others but within the boundaries of expected behaviour. By implication as an elite father, who is a teacher is expected to deliver lectures, assignments, homework, prepare examinations and also be dedicated concerned, honest, responsible, entrepreneur, a father, and be patient with each of these roles, obligation, privileges, tight vis-à-vis other persons. As the population continues to grow, the literate population grows. There is always the broadening of political participation, institutional revolutionary organization and parties, socio-economic reform, expanding roles of the state in large-scale intervention in the economy. It is visible that political change in turn affects the courses of socio-economic development. However, these are not without challenges. Such as short falls in formal education transportation, urban setting, confrontational social ills and growth of population.

Close to this, is the impact of outside events not only on economy but also politically through wide spread imported ideologies of socialism, communism and fascism. For example Europeans were influenced by breakaway, a socialists a communist parties eventually found in their own countries, communities. All nations of the world are more or less diverse with respect to ethnicity or race. A group is view as distinct, due to its nationality, cultural, religious, linguistics or other attributes. Ethnicity of a population is looked at in terms of geographical distribution, urbanization, population change, population composition, development trends and uses of land and resources are modified in the expansion of growth, industrial expansion, accelerating technologies change. These are only possible in times of population stability achievable through reorganization, a rearrangement of activities for a better environment relationship and stability by extension, for example countries like Japan, I reland, Sweden etc.

Huntington (2000) postulates that culture refers to the entire way of life of a society, its values, practices, symbols, institutions and human relationship. African countries have rich cultures. The ethnic groups have many unique varying cultures such as Nigeria. As much as these cultural practices, inhibit developments, so also are many forms of competitive struggles. The uniting force remains love, peace, tolerance and understanding, enforced by national ethnic. Like other countries of the world Nigeria's national ethnic shall be discipline, integrity, dignity of labour, social justice, religious tolerance, self-reliance and patriotism as content in Nigeria's 1999 constitution section 23. However, cases of discrimination and marginalization of certain members of the population have been identified as constraints to true and sustainable development. This lay question to the practice of federalism and democracy. In respect to ethnicity, segregation faulty application of National ethics and cultural practices could breed unrest. In Nigeria for example developing the girl and the woman has been contentious issue. Problems identified were linked to (1) Access to development resources, (2) health and reproductive rights, (3) Economic empowerment etc. 
Osahor (2005) opined that every nation has its aspiration and its core values, ethics, and national ethos, derived from those aspirations. It is prompt to remember that, national values guide his performances, attitudes, work ethics and expertise of the citizen. It is because of those values that citizens protect state properties, funds and National assets. Conclusively the individual citizen has fundamental rights and privileges and also has other duties to the nation. The population regardless of multiples membership to social groups where it is allow for rights to overlap the rights of others, there is spill over discontent, unrest, chaos and confrontationally. Education is a powerful tool for the said economic and political integration of the population. African Government must fulfill their commitment to the principles of the 1990 world Declaration on Education for all. Social skills are skills individual acquired through training that help in the development and transformation of the population. As new inventions help introduce new paradigms skills and development. Good neighbour policy has also helped in the education sector. The evidence of education has continued unabated collaboration came on as philanthropic organizations, multi-nationals, NGOs, international communities and donor agencies collaborated on so many projects, Platforms. However, this cannot be said to occur without challenges.

\section{Population and Family Role Modification}

The family is a basic Kinship Unit, in its minimal form is a small group. In its widest sense it refers to all relatives living together, well recognized to all relatives living together, well recognized as a social unit Marj (2006). There is esteem family companionship among members A types of family transformation in which behaviour is based on the roles and functionalism of its members. Individual behaviour is determined and guided by cultural and members group influence with psychological, biological, geographical and climatic factors as determinants of social behaviour. These intune teleguide the individual members of the family towards family values, morals, ideals, beliefs and behaviour acceptable.Differential distribution of life chances in the family as determinant by the status of the family can lead to uncontrolled situations.

Group formation within the population context can be small or large social system. The size of member can determined pattern of social relationship. Individuals in their free will can have multiple memberships. Where there role participation is to replicate and transmitted in societal values, norms, ideals, beliefs and behaviour. It is worth noting that population activities are controlled by these.

\section{Causes of Population Unrest}

1. Educational challenges (i) Inconsistency of policies. (ii) Poor funding in education sector. (iii) Regular hike in school fees. (iv) Military incursion culture into politics. (v)Corruption, frauds. (vi) Economic instability. (vi) Political instability. (vii) Ethnicity and tribalism, value change.

2. socio-political challenges (i) OAU-All making it more effective. (ii) Elected government to replace undemocratic ones. (iii) Fitting into Globalize world. (vi) Violence, conflicts, environment degradation. (v) Peace, security, terrorism, democracy and good governance.

3. Socio-economic challenges (i) Infrastructural development closing the gab. (ii) Economic and corporate governance. (iii) Human resource development. (iv) Consolidation of science and technology. (v) Capital flow. (vi) Disaster management. (vii) Regional organizations. (viii) Culture/institutions. (ix) Population problems. (x) Effects of family size, parity, and spacing on health. (xi) Consequences of rapid population growth on community, on health, on food production. (xii) Inquiry-oriented teaching unit on population growth and economic progress. (xiii) Inquiry approach to effects of population growth on socio-economic development. (xiv) Delayed versus early marriage on population. 
Impairment of peace and order have recorded some negative imparts. Some of which could described in this manner. Observation from different levels of the peoples' parliament on security backdrops and unrest, could be situated on a number of factors, some point fingers at politicians, administrators, military interventions, disregard for laws and non-compliance to affective domain indices and principles.

Haruna (2012), cited by Tamitope (2012) were of the opinion that poverty was not the immediate cause of unrests and terrorist insurgency. They maintained that the menace has been as a result of much injustice and corruption. Unless we begin to tackle issue of corruption, unless we are sincere with the governed, more terrorists group will continue to emerge. He added that until the problems of poverty, unemployment greed, and total lack of amenities, amongst others are solved, more terrorist groups will continue to emerge to agitate for their rights. Northern leaders are to be blamed for their inability to reach out to the masses.

Nigeria could be said to be a lawless society, because there is no culture of transparency in some sections of the economy, such as crude oil theft, money laundry, immunity to some few individuals etc. sometimes the only get see the facts only after an individual has left the office. Of grave concern is the up most disregard for laws, to deal with situations. Government must be ready and be able to enforce them. Achufuna (2012) was prompt to ask, what Nigeria law prescribes sanctions for terrorism? What statute prescribes punishment for mass murder? Terrorism and instability currently experienced in most parts of Africa, blames rest on the door steps of elites. In Nigeria despite huge security votes to governors have failed to checkmate acts of insecurity, Oduenyi, (2012).

Cases of over heated constitutional crisis resulting from misapplication of democracy. If you violate the principles of one man, outvote rule you are not in tune with democracy. This is in the constitution a provision for immunity for certain categories of public officers, like the governors, members of the National assembly are indirectly enjoying and asking for immunity. The policy of federal character in employment, education, political office appointment etc, has brought impact of dichotomy.

Most African countries do not have a coordinated security agents that is as good as America's $\mathrm{FBI}$ and $\mathrm{ClA}$. The crimes in contemporary African communities have assumed different dimensions, the different security operation lack operational networking from grassroots to the states and to the capitals. There is the absence of regular training, practical exercises in hand-on techniques etc.

The security of a population becomes encompassing, only when the arsenals or structure required for it's to work are fully in place. Countries the world over are not leaving a single stone unturned on ensuring maximum national security in critical areas as food security, health security, political security, economic security, social security etc. These underlying issues impairing on countries national security; building national unrest, are also being echoed among the population and families, as concerned issues.

African countries are diverse in ethnic groups. The diversity that characterized the population of 250 ethnic nationalities, instead of being formidable, united and a source of strength, has been great source of weakness and strain. In addition, the federal formations in Nigeria lack the element of cooperation among the federal units, the states. Further more, the security of any population depends heavily on the internal socio cohesion. This very condition is apparently lacking in Nigeria. Dissenting opinion, usually reflect the ethnic diversity of the population. The re-naming of University of Lagos. Finally, Nigeria suffered long period of democratic and political incarceration from the military. The domineering posture of the military, hardly promoted internal national cohesion. Most after maladministration in Nigeria has set citizens at odds. Forces of disunity that had characterizes the civil society had crept into the military. Federalism in Nigeria has not adequately addressed the question, the widespread cry of marginalization, domination, neglect of the minority, under the control of the majorities in Nigeria. 


\section{Curbing Unrests and Security Challenges.}

In tune with demographic process analysis have shown that the size, composition, distribution pattern of change overtime, are determinants and consequences of change are useful pivots, instruments particularly to the government for policy formulation that would otherwise take charge of unrest in critical areas of health, education, housing, security, unrests, employment and environmental preservation. Ekpo, (2012) He added that cumulative treatment of these issues is a better diversion as they have the capacity to provide vital information, knowledge, modified demographic that can do away with unrests insecurity etc.

Elaigwu, (2004) observed that attempts to deal with well defined problems of negative inpact in isolation only create confusion and disaster. In his remark, he added that social problems are problems, considered personally or socially harmful, generating undesirable conditions, unrest and situations such as Juvenile delinquency, addition, crane, prostitution, divorce, chronic unemployment, poverty, mental illness, gambling, narcotic trafficking, social deviants, profiteering, social conflicts existing. Conclusively, it is acceptable that social and political problems are interwoven, so most be tackled wholesomely not by itemization.

Apart from the developed countries, developing countries are small in form of per capita incomes as a result they have hunted markets and investment potentials. Investment grossly depends on economic of scale for viability. The call is for small countries to adopted regional and sub regional approach to economic integration and development, in order to improve international competitiveness. Individual communities have a major role to play in promoting economic growth and development by implementing poverty reduction programme in skills development, entrepreneurships, etc, to ensure sustainability. There is the need for utilization of funds, that has benefited several economies, as in agriculture commerce, industries, etc, resulting in stronger economic growth and higher productivity levels. Also by facilitating company growth, opportunity for small investors, merger agreement through stock market, raising capital for business, and providing barometer of the economy to show signs of stability, growth, or otherwise depression or funeral crisis and economic recession (NSE, 2006).

Building community infrastructure in areas of power plants, water sanitation, roads, bridges, railways, airports, highways, water ways and telecommunication facilities. Infrastructure is major parameter for economic growth, productivity, poverty reduction, cost and reliability services. Repressive regimes as of Mummar Gaddafi of Libya, Egypt Anwar Saddat, Albashar Alhasad of Syria are being replaced by democratically elected governments.

The environment the entire population is now a globalize world. This phenomenon has led the black continent to think more about taking charge of its future to minimize unrests. transformed the previous Pan-African body, the organization of African Unity, into anew, more effective African Union. The efforts made African leaders to adopt the new partnership for Africa's Development (NEPAD) of a July 2001 summit.

In this line-up is the exhaustive concepts of democracy and good governance. This entails good leadership. Those who control political power at any point in time, control the destiny of such a nation. A leadership in a democratic set up entails that the political institute landscape is a one man one vote rule of democracy, accountability and leadership that would allow political stability and administrative efficiency to flourish is most welcome.

Peace and stability are achievable through development of scopes of universally accepted behaviour. On that one would incline to world citizenship responsibility, egalitarian attitude acceptance of non-violence and non-confrontational search for alternatives is emphatic. These scope of knowledge can arrived at through security and peace education that embrace concepts of conflict management, resolution, cooperation and interdependence, none-violence practices, global community, multicultural understanding comparative system, world order, global institution alternative security system, human rights, social justice, economic justice, political freedom, social responsibility, citizenship, stewardship world resolution. 
The new digital system has lots of investment, information and communication technologies. The convergence of computers, telecommunication and traditional media are crucial for the knowledge based economy. The new ICT initiatives have opened new windows of opportunity to accelerate economic growth and development in areas of intra-regional trade, accelerate integration into global economic of a common market. It is an impetus to the democratization process and good governance. ICT, a helpful tool for a wide range of applications, such as remote sensing and environmental, agricultural, infrastructural planning etc. Inadequate access to affordable telephones, broadcasting, computers and the internet Low African teledensity are the visiting obstacles.

Education has been a stabilizing agent in most communities remain low service costs are high, when these are removed. Because of this international donor have been in the forefronts of educational improvement in areas of universal primary access, secondary education, expenditure on education, introduction of ICT in primary schools improvement on curriculum development and access to ICT.

\section{Conclusion}

The security challenges that have bedeviled the African, Nigeria as a nation, such as the spade bombing, armed robbery, greed, assassinations, kidnapping, cultism, murder, pick pocketing etc. pose a lot of concern. African countries have derailed from the path of prosperity. As the tree bed, so will the tree be inclined Nigeria has bent, so shall it include. The moral values of being our brothers keep has eroded, we are no longer custodians of roles model ethics and community participation among parents, youth and individuals have eroded. People are no longer custodians of peace, stability and the laws. In addition offences such as lying, misrepresentation, fraud, cheating of any kind have continuously defy the powers and authority of religion and so have felled to inculcate moral values among adherence. Nigeria is only but a dwelling place that is in dare need of love and security. The home is a very important place in the world. The home, the family determines the moral state of the nation. It is well known that major criminal behaviours come from divided, unhappy homes. Parent should avoid being too permissive. The government and in their fit should ensure that children watch educative and good movies, films but not phonographic pictures.These be avoided because they have a corrupting nature and are probably society's worst enemy today. The greatest thing spouses can give their children is respect for each other and good moral upbringing. Parents are called upon to embark on early molding as this will help children learn more and faster more than it can be imagined. It must be remembered that domestic blessings are obtained regardless of family income. The secret of a happy home is genuine love to each other and to the nation for stability and control.

\section{Recommendations}

There is nothing wrong with forms of political education, civil education, economic education, science education, sociology education, business education, engineering education, vocational education, technical education etc. They are called disciplines because they are embedded with positive attributes connecting the cognitive and psychomotor learning. It is unthinkable for educationist to now say that disciplines have generated indiscipline, insecurity unrest by extension. The security challenges facing the communities is the refusal by individual within the population to exercise their positive self, aspects of life. Instead they prefer to exhibit the negative self by their reasoning, and not to suppress their conscience; this has developed over time and is connected to the affective domain learning where implementation of positivism of learning, education rest. Therefore one is of strong opinion that for a meaningful national security, attitudinal changes should be the focal point tailored towards potisitivism. 


\section{References}

Achufuna, K. (2012). Nigeria needs laws to tackle television. The source magazine July 30, 2013. By summit publication limited. 30 Emina Crescent, Ikeja, Nigeria

Biology (2010) (e.d) Edua, R.G. (2012). Encyclopedia Britannica, Encyclopedia

Britannica students and home edition. Chicago; Encyclopedia Britannica.

Bola, K. (2012). Interview by Tajudeen, S. with Brig Gen. Bola, K. director Army public relations. Tell magazine August 20, 2012. By tell communication limited 22 Lagos-I badan expressways, Lagos.

Ekpo, A-H. (2012). State G.D.P.'s and Nigeria's economic growth. Tell magazine September 3, 2012 by Tell communications, kilometer 22, Lagos-IbadanExpressway Ojodu, Ikeja, Lagos.

Ekpo, A-H. (2012).must the tribes die in a new Nigeria? Tell magazine August 20, 2012. By Tell communication limited. Kilometer 22 Lagos-I badan Expressway,Ojodu, I keja, Lagos.

Elaigwu, J.I. (2004). The challenges of nation building in the Twenty-First century: the Nigerian experience. Benga IPPA distinguished lecture delivered atthe University of Calabar, May 13, 2004, Clear lines publications, Calabar, Nigeria.

Huntington, A.P. (2000). Culture counts. In Hrison, L.E. and Huntington, S.P. (eds). Culture matters: How values shape human progress. New York: Basic.

Haruna and Temitope, A. (2012). Dissenting the roots of Boko haram. Tell magazine, august 20, 2012. By Tell communication limited, kilometer 22 Lagos-I badan Expressway, Ojodu, Ikeja, Lagos.

Life (Biology) (2010) (e.d) Edua, R.G. (2012). Encyclopedia Britannica, EncyclopediaBritannica students and home edition. Chicago; Encyclopedia Britannica.

Labour Law (2010). Encyclopedia Britannica, Encyclopedia Botannica student and home -edition. Chicago; Encyclopedia Britannica.

Food Security (2012). Encyclopedia Britannica, Encyclopedia Britannica studentand home -edition. Chicago; Encyclopedia Britannica.

Marj, O.H. (2006). Academic's Dictionary of sociology. Printed by star Off-set printers, New Delhi, India.

Oduenyi, (2012). Foundation for sustainable peace and conflict resolution in Africa.NGO. Berates governor for crisis in the North, Tell magazine, September3, 2012. Tell communications, kilometer 22 Lagos-I badan, expressway, Ojodu, I keja, Lagos. 
